\title{
Una peseta para el teatro y en el pecho una flor para escuchar la retreta: entretenimientos de la sociedad griega en la primera mitad del siglo XX, Costa Rica
}

\section{A Quarter for the Theater and a Flower on the Vest in Order to Listen to the Concert: Grecia's Society Entertainment in the First Half of the XX Century, Costa Rica}

\begin{abstract}
Yendry Vargas Trejos*
Resumen: Este artículo analiza cómo ente 1920 y 1960 la comunidad griega disfrutó su tiempo libre a través de la música, los bailes, el teatro y los clubes sociales. Se explica de qué manera la conformación de un espacio social más urbanizado facilitó la apropiación de expresiones de ocio y hábitos de esparcimiento semejantes a las practicadas por la burguesía josefina. El estudio se basa en información del Archivo Nacional, actas municipales, periódicos, fuentes orales y documentación fotográfica.
\end{abstract}

Palabras claves: ocio; entretenimiento; cultura; socialización; espacio urbano; historia; Costa Rica.

Abstract: The aim of this article is to analyze the way how the community of Grecia (Costa Rica) spent their free time between the 1920s and the 1960s by means of enjoying music, dances, theater, and places of social gathering. The way how the conformation of a more urban social space facilitated the appropriation of leisure expressions and recreational habits similar to the ones practiced by the bourgeoisie in San José (the capital city) is explained in the article. The research 
is based on information gather from the Archivo Nacional of Costa Rica, Grecia's Town Hall files, newspapers, interviews, and photos.

Keywords: leisure; entertainment; culture; socializing; urban space; history; Costa Rica.

\section{Introducción ${ }^{1}$}

$\mathrm{D}$ urante las primeras décadas del siglo XX el casco central de Grecia fue por excelencia el espacio idóneo para la diversión y el esparcimiento. La música, los juegos de azar y los bailes de sociedad permitieron a la población griega establecer vínculos de amistad y expresión cultural. Se contaba con un cuerpo de filarmonía, con un teatro, un salón de cine, y lugares de socialización como el Centro Obrero, el Club de Amigos y el Grecia Fútbol Club. El auge de dichos espacios permitió, especialmente a los varones, encontrarse para disfrutar de forma privada su tiempo libre.

En este artículo se analiza de qué manera, mientras el cantón experimentaba importantes transformaciones socioeconómicas asociadas al cultivo de la caña de azúcar y al café, obreros, comerciantes y agricultores lograron conformar una cultura de ocio y recreación. Es decir, de diversión pública rural, donde el teatro, la filarmonía y los clubes sociales jugaron un papel predominante. Se parte del supuesto de que el proceso de conformación de un espacio social más urbanizado facilitó la apropiación de estas expresiones de esparcimiento. Es así como, a partir de 1920, la comunidad griega disfrutó sus tiempos de ocio reproduciendo formas de diversión practicadas por la sociedad josefina.

El proceso de conformación de un espacio social con características urbanas y las distintas manifestaciones culturales de ocio y recreación que en él se expresaron a lo largo del periodo de 1920-1960 fueron investigados mediante la consulta de fuentes primarias provenientes del Archivo Nacional, actas municipales, periódicos y libros de actas de los clubes sociales. Asimismo, se recurrió a la fuente oral para conocer de qué manera la juventud de esos años dio significado al contexto histórico en el que convivió ideando formas de divertirse, compartir y socializar.

1 Este artículo presenta hallazgos de una investigación realizada en el año 2001 concerniente al desarrollo del movimiento comunista en el cantón de Grecia. Se dedica este escrito a todas las personas adultas mayores que compartieron sus recuerdos de juventud, especialmente a Juan Rafael Morales Alfaro.

También se agradece a Rodolfo Barillas Acosta y a sus fieles seguidores del Facebook Personajes de Grecia: https://es-la.facebook.com/PersonajesGrecia/ por el aporte del recurso fotográfico, y su esfuerzo en ubicar datos cronológicos y temáticos de las fotografías expuestas en este estudio. Se extiende el agradecimiento a Lucila Ramírez Arguedas por compartir la colección fotográfica de su familia en relación a la conocida Botica La Violeta, la cual fue fundada por su abuelo Luis Ramírez Zamora y conservada hasta su muerte por su padre Luis Ramírez Villalobos, ambos conocidos como los boticarios de Grecia. 
Se entrevistó a un total de nueve personas mayores, seis varones y tres mujeres, quienes al momento de la entrevista tenían entre 70 y 90 años. ${ }^{2}$ Todas estas personas, a excepción de dos de ellas, nacieron en el cantón de Grecia. Sus padres y abuelos se dedicaron principalmente a la agricultura y a la ganadería, aunque también trabajaron como obreros, comerciantes y funcionarios municipales. Cinco de los varones entrevistados tienen en común el hecho de haber trabajado en labores de zapatería, uno de los principales gremios de producción presentes en el cantón durante el periodo de estudio.

A estas nueve personas se les aplicó una entrevista estructurada que abordó temáticas asociadas con las características de su núcleo familiar, así como recuerdos del proceso de urbanización del casco central del cantón, tipo de actividades agrícolas, comerciales y de servicios que para entonces se desarrollaban; y formas de divertirse y disfrutar tiempos de ocio. También se recurrió al recurso fotográfico mediante el cual fue posible dar significado a los discursos de estas personas, y analizar las diversas formas en que la sociedad griega disfrutó de los juegos de azar, el teatro, el deporte, la música y los bailes.

Este artículo ha sido organizado en cuatro apartados generales. El primero analiza las líneas teóricas que permiten comprender las manifestaciones del ocio y la recreación en un tiempo y espacio sociohistórico determinado. En el segundo, se estudia de qué manera el casco central del cantón fue experimentando un proceso de transformación gracias al desarrollo de nuevas actividades comerciales y a la oferta de numerosos servicios, lo cual facilitó la adopción de formas de socialización y diversión propias de la sociedad urbana josefina. Los dos últimos apartados describen de qué forma la comunidad griega disfrutaba su tiempo libre asistiendo al parque a escuchar recreos y retretas, participando en clubes sociales y, en definitiva, bailando y gozando la puesta en escena de funciones teatrales y películas.

\section{Las manifestaciones culturales del ocio y la recreación}

Para comprender e interpretar la forma en que la comunidad griega disfrutaba su tiempo libre, este artículo analiza el ocio como una práctica sociocultural y una necesidad humana, en tanto se acerca al concepto de recreación como el repertorio de actividades sociales mediante las cuales se busca satisfacer la necesidad de ocio. En el diagrama 1 se muestran las líneas interpretativas sobre los conceptos de ocio y recreación en que se enmarca el estudio.

2 De acuerdo con la Estrategia Nacional para un envejecimiento saludable basado en el curso de la vida 2018-2020, el concepto de personas mayores debe ser empleado cuando se hace referencia a toda persona de 65 años o más. Al respecto, consultar: Ministerio de Salud. Dirección de Planificación Estratégica y evaluación de las acciones en salud (1ª . ed. San José, Costa Rica, 2018). 
Diagrama 1. La dimensión cultural del ocio y la recreación

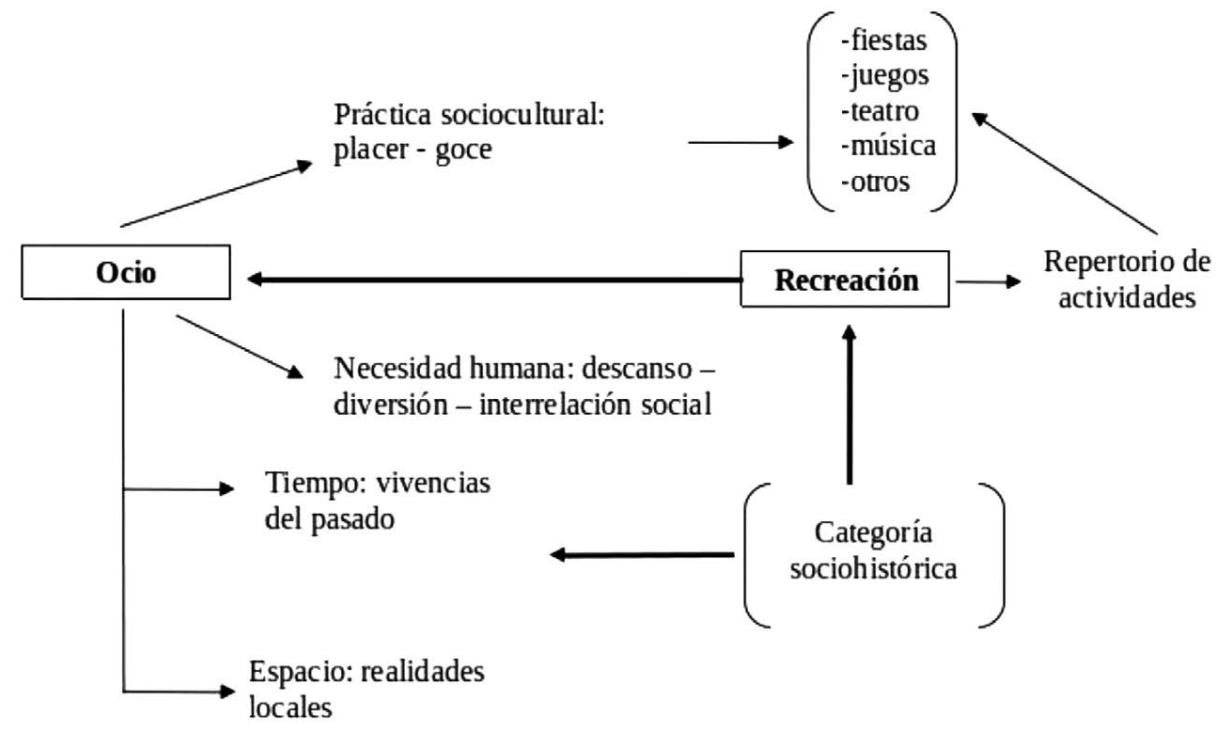

Fuente: Elaboración propia.

Partiendo de la conceptualización de ocio como una dimensión de la cultura históricamente situada, que está en íntimo diálogo con el espacio y las realidades locales, se comprende este como una práctica social contextualizada. Es a través de él que las personas construyen y resignifican, en sus propias temporalidades, las vivencias sociales vinculadas al goce y al placer. ${ }^{3}$ Cada pueblo y cada sociedad construyen y significan sus propias prácticas socioculturales de ocio para vivirlas como disfrute de la cultura. De allí que el ocio haya sido interpretado por algunas investigaciones latinoamericanas como una categoría histórica. ${ }^{4}$

Ello, por cuanto, aunque las experiencias del ocio transcurren en el tiempo, a la vez también son y se califican, gracias al tiempo. Es decir, el tiempo incide en la vivencia del ocio, no solo desde un punto de vista histórico, sino porque está marcado por las vivencias del pasado. Las distintas expresiones de ocio no son solo presentes, sino itinerarios de vida que están marcados por un tiempo propio. ${ }^{5}$ En tal caso, las diversas manifestaciones del ocio: fiestas, juegos, paseos, música, teatro, deportes, poesía, o bailes, entre otras expresiones, asumen un

3 Christianne Gomes, «Ocio, recreación e interculturalidad desde el 'Sur' del mundo: desafíos actuales». Polis: Revista de la Universidad Bolivariana, 9, n. ${ }^{\circ} 26$ (2010), doi: http://dx.doi.org/10.4067/ S0718-65682010000200010.

4 Christianne Gomes, «El ocio y la recreación en las sociedades latinoamericanas actuales», Polis: Revista Latinoamericana, 13, n. 37 (2014), http://journals.openedition.org/polis/9905.

5 Manuel Cuenca Cabeza y Eduardo Aguilar Gutiérrez, El tiempo del ocio: transformaciones y riesgos en la sociedad apresurada (Bilbao, España: Universidad de Deusto, 2009). 
papel peculiar para sujetos, grupos sociales, instituciones y sociedad que les dan un significado histórico, social y cultural en un tiempo y espacio específicos.

Desde tal punto de vista, el ocio es concebido como un concepto más amplio que la recreación. Ya que esta es asumida como una de las posibles formas de satisfacer la necesidad de ocio. Por ello, es importante comprender que el ocio puede incluir a la recreación, lo que no ocurre de forma inversa. De allí que desde lo conceptual, el ocio y la recreación sean diferentes. ${ }^{6}$

$\mathrm{Al}$ concebirse el ocio como una experiencia humana necesaria a través de la cual las personas se divierten y se relacionan socialmente, este ha adquirido, en la actualidad, una visión más positiva, ${ }^{7}$ pues ha dejado de ser identificado solo con el descanso, los feriados, y la diversión, o en peor medida, vinculado directamente a la vagancia, la pereza y el «no hacer nada». Su significación se ha ampliado como un derecho y un elemento que aporta a la calidad de vida y a la salud de personas y comunidades; es así capaz de proporcionar autorrealización. ${ }^{8}$ Desde tal perspectiva, la concepción social del tiempo de ocio varió en su definición pasando de entenderse como un «tiempo perdido» a considerarse el «verdadero tiempo vivido». ${ }^{9}$

Es precisamente allí donde el término recreación se colma de significados, pues se reconoce que las actividades recreativas posibilitan la expresión de nuevas necesidades y capacidades. En la modernidad, la recreación fue ideada como una herramienta para el mantenimiento del orden sociopolítico, y como un instrumento para la educación moral, con lo que se buscó higienizar y lograr la profilaxis social. ${ }^{10}$ Sin embargo, al incorporarse socialmente el derecho a una mayor disponibilidad de tiempo libre, se reconoce que las actividades recreativas posibilitan la expresión de nuevas necesidades y capacidades.

Desde tal óptica, la recreación alude al conjunto de prácticas de índole social realizadas colectiva o individualmente en el tiempo libre. Esta misma constituye un universo social de significados compartidos por una colectividad que expresa, con matices diferentes en cada sociedad concreta, las formas de alcanzar el disfrute y el placer públicamente. Se integra así la vertiente histórica que vincula a la recreación con necesidades y habilidades presentes en el mundo

6 Rodrigo Elizalde Soto, «Resignificación del ocio. Aportes para un aprendizaje transformacional», Polis: Revista Latinoamericana, n. ${ }^{\circ} 25$ (2010), http://journals.openedition.org/polis/642.

7 Etimológicamente la palabra ocio proviene del término latín «otium» vinculado a la noción de descanso y reposo, de retiro, soledad y tranquilidad. Posteriormente, en la Roma antigua, surge un concepto correlativo y opuesto al "otium" (ocio romano) el «negotium», que literalmente fue entendido como la negación del ocio, como el "no ocio" y que significaba básicamente «ocupación y quehacer», del cual deriva la palabra negocio. Para más detalle consultar: Rodrigo Elizalde (2010), 5.

8 Manuel Cuenca Cabeza y Eduardo Aguilar Gutiérrez; Christianne Gomes, «Ocio, recreación e interculturalidad...».

9 Ana Goytia Prat, «El influjo del tiempo en la experiencia de ocio de los vascos. Transformaciones en los últimos 15 años», en: El tiempo del ocio: transformaciones y riesgos en la sociedad apresurada (Bilbao, España: Universidad de Deusto, 2009), 221.

10 Elizalde Soto. 
laboral. Por ello, la importancia de incorporar en el análisis la influencia del contexto como categoría sociohistórica que condiciona las prácticas recreativas de la sociedad y los modos de construcción y apropiación del conjunto de saberes y formas de expresión culturales. ${ }^{11}$

Considerando que cada pueblo y sociedad construye y simboliza sus expresiones de ocio y recreativas en el tiempo, el propósito de este artículo es estudiar: ¿Cómo disfrutaba la sociedad griega de inicios de siglo XX su tiempo libre?, ¿cuáles fueron las principales formas de expresión del ocio y la recreación en este espacio social?, y ¿de qué manera la conformación de un espacio más urbanizado propició diversas manifestaciones del ocio?

\section{Entre cañales y cafetales se propicia un espacio social urbano}

Grecia fue un pueblo eminentemente agrícola, su «tierra saludable para todo fruto», permitió el desarrollo de un paisaje agrario muy diversificado. Al respecto, en 1911 el Estado costarricense consideraba que en «cuanto a valor y significación económica para el país, la región de Grecia es de las que figuran en primera línea por su producción de azúcar, dulce, almidón, café, frutas y cereales, es decir, de todos los artículos de primera necesidad para el pueblo costarricense». ${ }^{12}$

Hacia 1920 el cantón se posicionó como uno de los principales centros productores de azúcar y dulce del país. Para entonces habían establecidos cuatro grandes ingenios y cerca de 60 trapiches de agua. ${ }^{13}$ Ya en 1935, al sur del cantón, había una región extensa donde la caña dominaba casi completamente al café. ${ }^{14}$ Por tal razón, entre 1940 y 1945 el cantón fue concebido «como el centro comercial del ganado, del dulce y de los granos», ${ }^{15}$ y ocupó, según el cuerpo municipal, el «primer puesto en el país como productor de caña de azúcar». ${ }^{16}$

Uno de los aspectos que aceleró la expansión del cultivo de la caña fue la construcción a partir de 1928 de la carretera asfaltada entre la provincia de Alajuela y Grecia. La fotografía 1 muestra el antiguo camino de lastre que entre finales del siglo XIX y principios del XX comunicaba a la provincia con el cantón. Con la construcción de esta vía de comunicación se fortaleció el desarrollo

11 Julia Gerlero, «Diferencias entre ocio, tiempo libre y recreación: lineamientos preliminares para el estudio de la recreación» (Ponencia presentada en el I Congreso Departamental de Recreación de la Orinoquia Colombiana. Villavicencio, Meta. 20, 21 y 22 de octubre de 2005; Servicio de la Fundación Colombiana de Tiempo Libre y Recreación; FUNLIBRE, Costa Rica México) http://www.redcreacion.org/documentos/ cmeta1/JGerlero.html\#Uso_apropiado_del_documento.

12 Archivo Nacional de Costa Rica (ANCR), Fondo Congreso, año 1911, serie 76, folio 2.

13 ANCR, Fondo Congreso, año 1920, serie 11727, folio 1.

14 Carolyn Hall, El café y el desarrollo histórico-geográfico de Costa Rica (San José, Costa Rica: Editorial Costa Rica, 1982), 108.

15 ANCR, Fondo Municipal, año 1940, serie 016633, folio 332.

16 Municipalidad de Grecia, Libro de Actas No 5, Sesión XLIV, Artículo XIII (27 de junio de 1945), f.132-133. 
económico de Grecia, pues se facilitó la instalación y la modernización de los primeros ingenios. ${ }^{17}$

Fotografía 1. Antiguo camino de comunicación entre Alajuela y Grecia, siglos XIX-XX

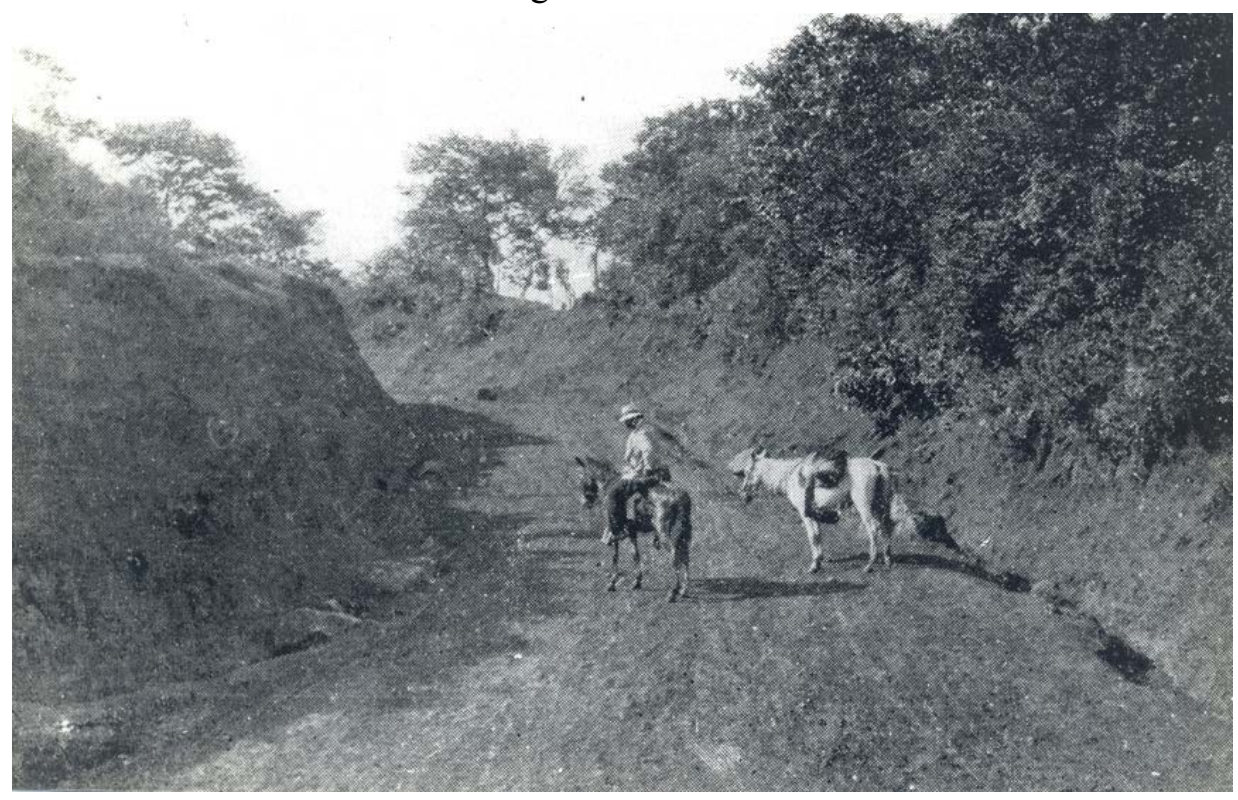

Fuente: Archivo Nacional de Costa Rica (ANCR), Fondo Fotografías, siglo XIX y XX, serie 74338 .

Para la municipalidad, las carreteras construidas vinieron a simplificar la distribución del artículo hacia las zonas que lo necesitaban. ${ }^{18}$ Pero, además, el crecimiento económico que alcanzaba Grecia a través de la industria azucarera fue identificado por el gobierno local como una oportunidad para la creación de impuestos. A partir de 1933 se gravó el quintal de azúcar en un colón con el fin de destinar la mitad de lo recaudado a la reparación y a la construcción de carreteras, caminos y cañerías. Con los impuestos recaudados se buscó fortalecer y promover el desarrollo urbano local. ${ }^{19}$

Asimismo, la consolidación de la agroindustria de la caña de azúcar contribuyó a que entre 1920 y 1930 el casco central de Grecia adquiriera una fisonomía

17 Carlos Alberto Maroto Barquero, Significado histórico, social y económico del café y la caña de azúcar en el cantón de Grecia (1892-1978) (Tesis de Licenciatura en Historia, Universidad de Costa Rica, 1979).

18 Municipalidad de Grecia, Libro de Actas No 5, Sesión XLIV, Artículo XIII (27 de junio de 1945), f.132-133.

19 Maroto Barquero, Significado histórico, social y económico..., 73. 
más urbana. El gobierno municipal promovió la construcción de edificios, el alumbrado público, la cañería, y trabajos de ornato como la reparación de calles y de caños cementados..$^{20}$ Además, resolvió pagar mensualmente la suma de 50 colones a un médico del pueblo y jefe de sanidad para la atención de la salud pública del cantón. ${ }^{21}$

También fueron contratados dos empleados por la suma de siete y nueve colones semanales para el aseo del mercado, edificios municipales, desagües y calles urbanas. ${ }^{22}$ La fotografía 2, que data de aproximadamente 1935, permite apreciar, hacia el costado sur del parque, el tendido eléctrico, la organización de calles y aceras, y parte del desarrollo de la infraestructura.

Fotografía 2. Construcciones al costado sur del parque, frente a la iglesia católica Nuestra Señora de Las Mercedes, Grecia (1935)

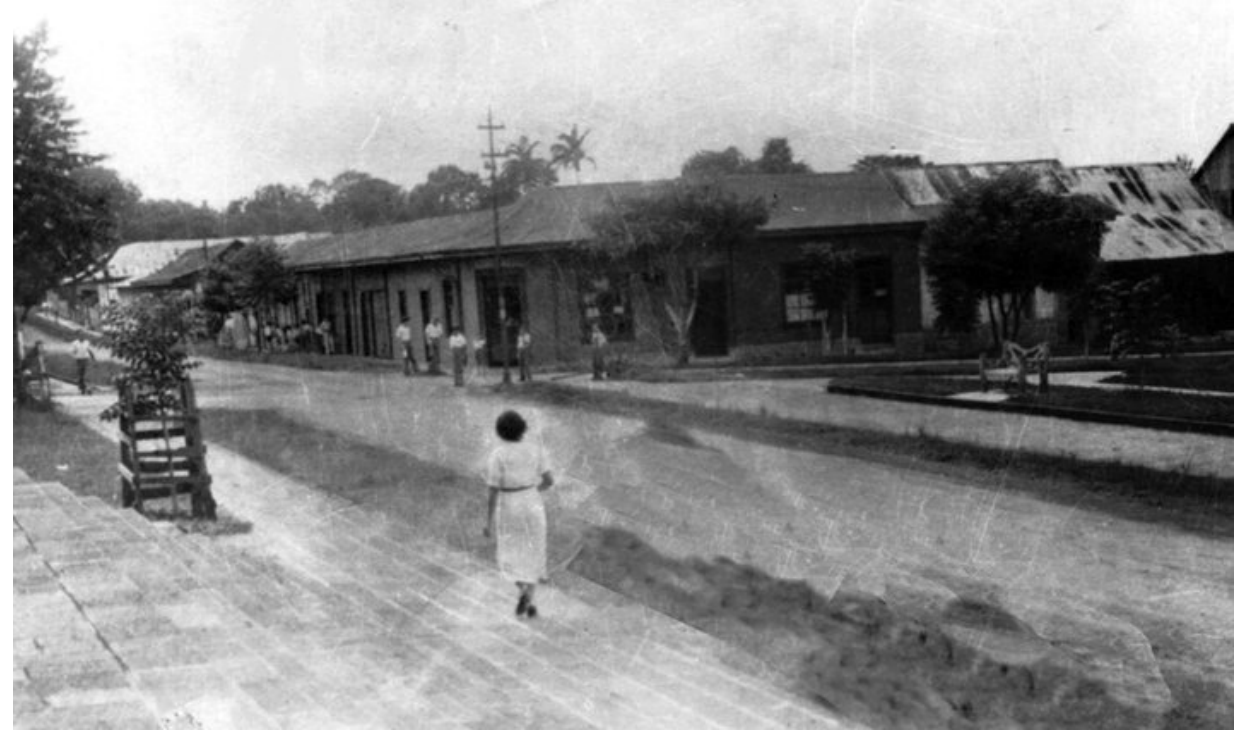

Fuente: Facebook "Personajes de Grecia", https://www.facebook.com/PersonajesGrecia/. Página administrada por Rodolfo Barillas Acosta. Diseñador gráfico y fotógrafo. Fecha aproximada.

Respecto del carácter urbano que adquiría Grecia gracias a mejores vías de comunicación y a la expansión de servicios públicos, en 1926 el periódico La Tribuna comentaba:

20 ANCR, Fondo Congreso, año 1936, serie 17609, folio 5. También puede ser consultado: Municipalidad de Grecia, Libro de Actas N. ${ }^{\circ}$ 4, Sesión XXXIX, Artículo XXIII (2 de mayo de 1945), f.99.

21 Municipalidad de Grecia, Libro de Actas N. ${ }^{\circ}$ 6, Sesión X, Artículo XXI (14 de febrero de 1927), f.563.

22 Municipalidad de Grecia, Libro de Actas N. . 9, Sesión VI, Artículo XIII (3 de julio de 1934), f.169. 


\begin{abstract}
Mejoran notablemente los trabajos emprendidos en la carretera de Alajuela a Grecia. De la carretera nueva hay ya más de siete kilómetros. El hospital está muy bien atendido, el mercado está ya al terminarse de construir, igualmente la pintura de la Iglesia. La situación comercial está muy bien por ser este uno de los cantones más ricos de la provincia. ${ }^{23}$
\end{abstract}

En cuanto al último punto anotado por dicho medio de comunicación, durante las primeras décadas del siglo XX el comercio local mostró un importante crecimiento. En 1922 funcionaba en el centro de Grecia la tienda de géneros de Pedro Barahona donde se vendías granos y tabaco. En la manzana oeste al parque el boticario Luis Ramírez Zamora, quien había migrado de Heredia, estableció en 1914 una botica y, posteriormente, una casa de refrescos. En esta misma cuadra se hallaba localizada la nevería y la cantina de Porfirio García, la tienda de Jesús Vega y el almacén de Otto Kopper que ofrecía un variado surtido de géneros, abarrotes, $\mathrm{y}$ hasta ferretería. ${ }^{24}$

Las fotografías 3 y 4 muestran las instalaciones de la botica de Luis Ramírez Zamora entre aproximadamente 1920 y 1940. En la primera imagen se observa la fachada, y frente a ella, se divisa un tipo de horqueta en la que las personas solían amarrar sus caballos. En la segunda imagen se distinguen las instalaciones internas de la botica y a Luis Ramírez Zamora sentado en una mecedora con sombrero.

Fotografías 3 y 4. Fachada de la botica de Luis Ramírez Zamora y sus instalaciones internas, Grecia (1920-1940)

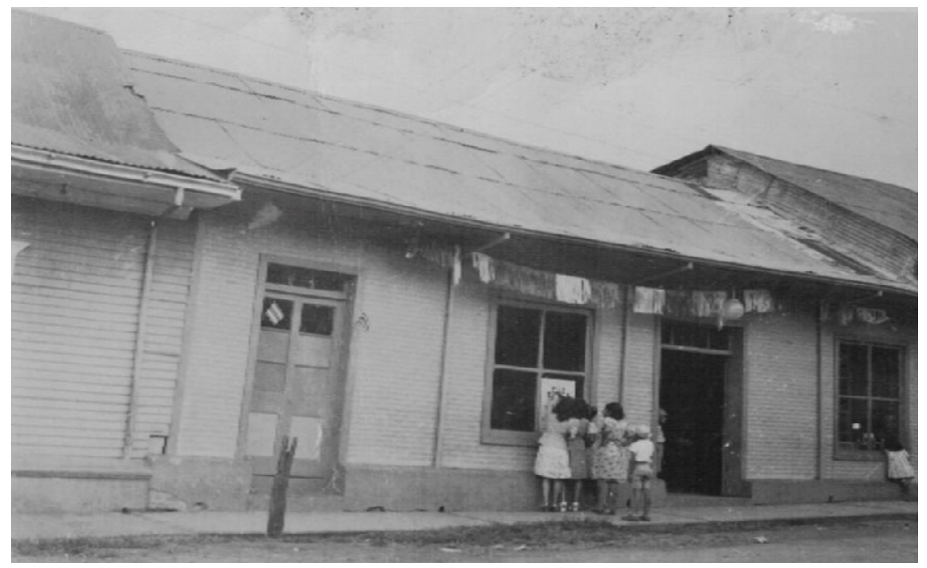

23 La Tribuna, «A través de la República, Grecia», 10 de marzo de 1926, 7.

24 Entrevista a Juan Rafael Morales Alfaro, vecino de Grecia, distrito central, Grecia, 25 de mayo de 2001, Adela Gómez Cordero, vecina de Grecia distrito central, Grecia, 25 de mayo de 2001, Mario Riggioni, vecino de Grecia distrito central, Grecia, 26 de setiembre de 2001, Ibeth Barrantes Vega, vecina de Grecia distrito central, Grecia, 24 de octubre de 2001. Información aportada por la familia Ramírez Arguedas, 4 de octubre de 2019. 


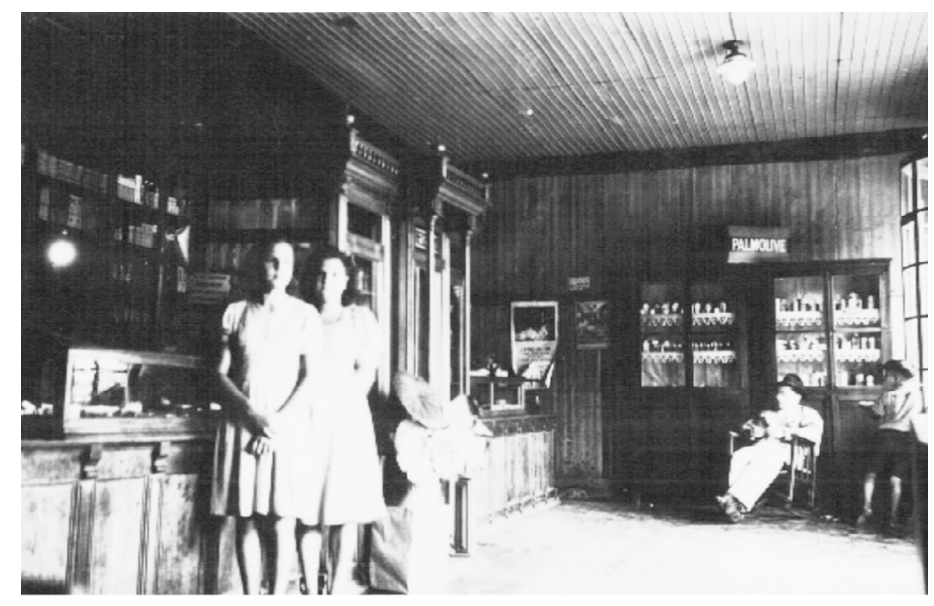

Fuente: Colección fotográfica de la familia Ramírez Arguedas, Grecia. Fechas aproximadas.

En aspectos de servicios y talleres, el cantón experimentó una importante expansión de oficios como la sastrería, la panadería, la ebanistería, la carpintería, la zapatería y la albañilería. De manera particular, la industria del calzado alcanzó un significativo crecimiento. Entre las principales manufacturas de calzado que se establecieron en el casco central se recuerdan las zapaterías de Francisco Cruz Aguirre, Gabriel Villegas, Alejandro Gómez y Elías Umaña. Este último taller se llamó La Norma y se menciona como una de las manufacturas de calzado más desarrollada del cantón, pues contaba con un contrato con la United Fruit Company y producía calzado para los trabajadores de la bananera. ${ }^{25}$

La zapatería La Norma estuvo localizada al oeste del parque. Juan Rafael Morales Alfaro, zapatero y líder comunista, quien nació en San Rafael de Poás en 1913, y trabajó por cinco años en esta zapatería hasta su despido en 1938, plasmó sus recuerdos de La Norma en la figura 1. Sus memorias guardan similitud con los detalles de la fotografía 5 en la que se observa el edificio blanco y con alero donde se ubicó la zapatería, contiguo al edificio con ventanas de la antigua escuela Eulogia Ruiz.

En cuanto al desarrollo socioeconómico que para entonces experimentaba Grecia, Juan Rafael Morales Alfaro menciona que cuando su familia, conformada por once miembros, llegó a Grecia:

El cantón de Grecia se desarrollaba. Se producía dulce en cantidad, azúcar que llenaba las necesidades de consumo del país. La producción de azúcar necesitaba de muchos trabajadores que consumían ropa, calzado. La producción cañera, del

25 Entrevista a Juan Rafael Morales Alfaro; Ibíd., Mario Riggioni, Ibíd., Ibeth Barrantes Vega. 
dulce y del azúcar, generaba otras demandas de productos en las sastrerías, panaderías, mueblerías, talleres y comercio. ${ }^{26}$

Figura 1 y fotografía 5. Ubicación de la zapatería La Norma contiguo a la Escuela Eulogia Ruiz
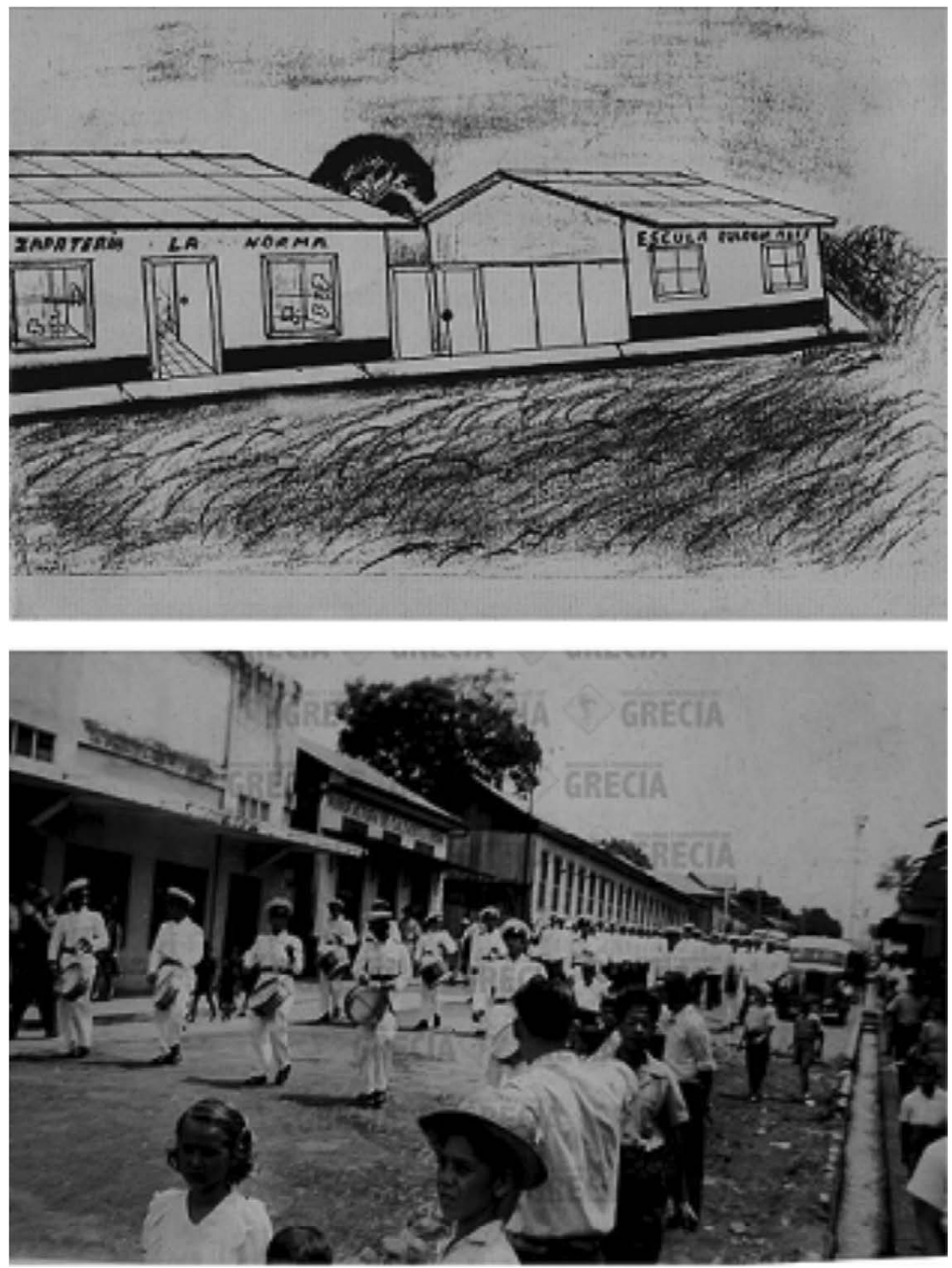

Fuente: Imagen dibujada por Juan Rafael Morales Alfaro (mayo, 2001). Fotografía tomada del Facebook "Personajes de Grecia", https://www.facebook.com/PersonajesGrecia/. Página administrada por Rodolfo Barillas Acosta. Diseñador gráfico y fotógrafo. Fotografía sin fecha.

26 Juan Rafael Morales Alfaro, Escribo para recordar (San José, Costa Rica: ASEPROLA-Universidad Estatal a Distancia, 2000), 13, 22. 
De la misma forma, Mario Riggioni, quien nació en 1914, y fue hijo de un electricista que migró de Heredia a Grecia con el fin de instalar la primera planta eléctrica, comenta que cuando su familia se estableció en el centro del cantón, siendo él un niño, en Grecia existía ya la posibilidad de trabajar en distintos oficios. A partir de los trece años él decidió dedicarse al oficio de zapatería: «Porque aquí cuando yo me criaba había que aprender zapatería, ebanistería, carpintería, sastrería, eso eran como ocupaciones. De las familias salían, el papá era, después el hijo mayor, y después otro»». ${ }^{27}$

Este paulatino proceso de conformación en la cabecera del cantón de un espacio social ligeramente más urbanizado se da en un momento en el cual el mismo país experimentaba un evidente desarrollo urbano. Entre 1950 y hasta aproximadamente 1980, el crecimiento del sector industrial, la expansión de los servicios, y las diversas actividades financieras y comerciales provocaron la transformación de zonas agropecuarias en San José y Alajuela. Estos cambios de la economía costarricense tuvieron una profunda incidencia en el desarrollo urbano de zonas rurales y alejadas de la ciudad capital, como fue el caso del cantón de Grecia. ${ }^{28}$

\section{El disfrute de tiempos de música, teatro y tertulias políticas}

Las sociedades filarmónicas fueron impulsadas en el país durante las últimas décadas del siglo XIX, y principalmente en el gobierno de Rafael Iglesias (1898-1902), quien propició la venta, a bajo precio, de instrumentos musicales. ${ }^{29}$ El cuerpo filarmónico de Grecia se fundó en 1893 con el objetivo de estimular la cultura del pueblo por medio de la música. ${ }^{30}$ Así lo concebía Isaac Barahona, director de la filarmonía del cantón, para quien las bandas de música y filarmonías eran las instituciones encargadas de «difundir el arte musical como medio de expansión y cultura al pueblo, cuya influencia eleva poderosamente sus sentimientos apartándole a cambio del ruin vicio y corrupción». ${ }^{31}$

En aquel universo rural, la filarmonía con su música vino a amenizar cada momento de diversión pública, ya fueran estos de carácter cívico, religioso o político. Todos los jueves y los domingos la banda municipal daba conciertos en el quiosco del parque. Estas eran las llamadas retretas y recreos que se popularizaron en el país a finales del siglo XIX con la construcción de los quioscos en los parques. Los parques ofrecían la infraestructura propicia para que las bandas militares amenizaran estos espectáculos públicos. Cabe destacar que en las primeras décadas del siglo XX las retretas y los recreos fortalecieron la sociabilidad urbana.

27 Ibíd.

28 Guillermo Carvajal Alvarado y Jorge Vargas Cullell, «El surgimiento de un espacio urbano-metropolitano en el Valle Central de Costa Rica (1950-1980)», Anuario de Estudios Centroamericanos, 13, n. ${ }^{\circ} 1$ (1987), https://revistas.ucr.ac.cr/index.php/anuario/article/view/2866.

29 Francisco José Enríquez Solano, Diversión pública y sociabilidad en las comunidades cafetaleras de San José: el caso de Moravia (1890-1930) (Tesis de Maestría en Historia, Universidad de Costa Rica, 1998), 122.

30 Municipalidad de Grecia, Libro de Actas N. ${ }^{\circ}$ 6, Sesión III, Artículo I (24 de enero de 1927), f.545.

31 ANCR, Fondo Congreso, año 1934, serie 1750, folio 1. 
Asimismo, durante esos años, los gobiernos locales propiciaron la instalación de escuelas musicales infantiles, y asumieron el financiamiento de las sociedades filarmónicas. ${ }^{32}$ Por ejemplo, en 1927 el cuerpo municipal de Grecia acordó que, para poder ingresar a la filarmonía, la persona debía «ser mayor de 12 años, haber cursado la escuela primaria y ser de reconocida buena conducta». También estableció como lineamiento que la filarmonía:

Estaba obligada a dar conciertos en el parque de la Ciudad los días jueves a las ocho de la noche, y a las cinco de la tarde los domingos, además debe tocar las procesiones del jueves y viernes santos, el jueves de Corpus y el 24 de setiembre, el 15 de setiembre, diana, Te Deum y Fiesta Escolar y el $1^{\circ}$ de Enero Te Deum, además recreo y retreta los días de fiestas declarados oficialmente. ${ }^{33}$

La fotografía 6 muestra el grupo de 25 músicos que conformó hacia aproximadamente 1961 la sociedad filarmónica de Grecia. La banda posa en las gradas de la Iglesia Católica Nuestra Señora de Las Mercedes, y muestra la elegancia de los trajes e instrumentos utilizados. Con respecto al vestuario que lucen los músicos, es importante indicar que a partir de 1870 se dictaron decretos y acuerdos que establecieron que las bandas no solo debían ser agrupaciones grandes y ordenadas, sino además, bien uniformadas, que impactaran al público musical y visualmente. ${ }^{34}$

Fotografía 6. Banda municipal en las gradas de la iglesia católica Nuestra Señora de Las Mercedes, Grecia (1961)

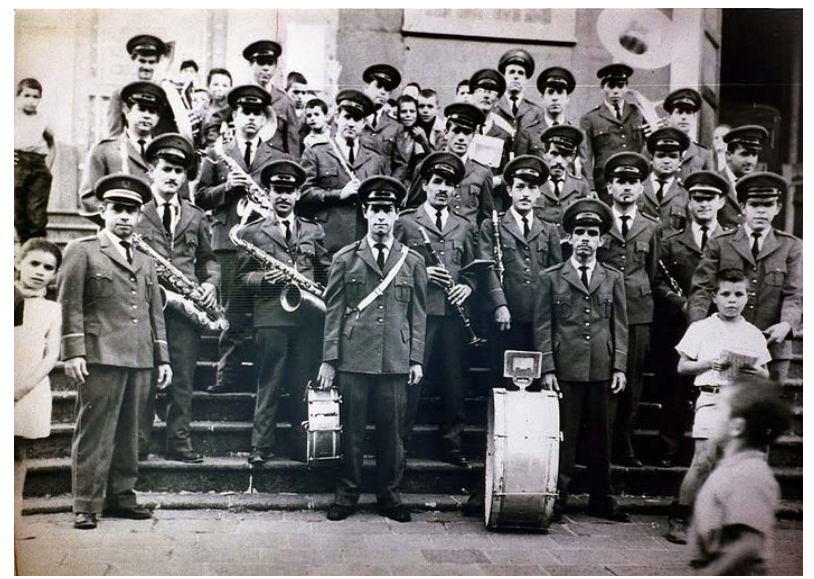

Fuente: Facebook "Personajes de Grecia", https://www.facebook.com/PersonajesGrecia/. Página administrada por Rodolfo Barillas Acosta. Diseñador gráfico y fotógrafo. Fecha aproximada.

Nota: Algunas personas amigas de esta red social se refieren a este grupo de músicos como "banda municipal”, y no necesariamente como grupo de filarmonía.

32 Francisco José Enríquez Solano, 123.

33 Municipalidad de Grecia, Libro de Actas N. ${ }^{\circ}$ 6, Sesión II, Artículo VIII (24 de enero de 1927), f.545-547.

34 María Clara Vargas Cullell, De las fanfarrias a las salas de concierto. Música en Costa Rica (1840-1940) (San José, Costa Rica: EUCR, 2004), 58. 
Álvaro Hidalgo Ramírez a sus 72 años comenta que desde muy joven se dedicó a la actividad comercial ayudando a su padre en la tienda de abarrotes que tenía ubicada diagonal al parque. Según expone, la sociedad filarmónica de Grecia estaba conformada así:

De 20 a 30 músicos que efectuaban un concierto de gala los domingos a las 7 de la noche en el parque, y un recreo a las 5 de la tarde. Acompañaban ciertas procesiones, la Misa de Tropa, y entre semana había un concierto los miércoles o los jueves. El quiosco era exclusivamente fabricado para que la banda pudiera tocar. ${ }^{35}$

Asimismo, Manuel Antonio Soto Barrantes, quien en su juventud fue ebanista como su abuelo, para posteriormente ser conocido por «la gente del centro» como el reparador de radios y artículos electrónicos, menciona que cuando la filarmonía tocaba: «El parque se llenaba, venían de los distritos a oír la retreta, y mientras unos deban vueltas, otros se sentaban». ${ }^{36}$ De manera similar, Juan Rafael Morales Alfaro, zapatero de 86 años de edad, describe sus recuerdos acerca de la filarmonía: «El pueblo contaba con una filarmonía que tocaba los domingos en el Parque unas magníficas retretas. Los jóvenes y las personas ya maduras, unos en parejas, dábamos vueltas y vueltas alrededor del Parque, en grupos de uno y otro sexo, disfrutando las sonoras melodías» ${ }^{37}$

La dinámica de dar vueltas al parque mientras la filarmonía tocaba fue una actividad practicada por la burguesía cafetalera josefina, la cual, además, se vestía de traje, sombrero y abrigo para asistir a escuchar las retretas. ${ }^{38}$ A sus 92 años de edad los recuerdos de Adela Gómez Cordero, contadora de profesión e hija de un contador y funcionario municipal, permiten identificar similitudes en los códigos de comportamientos y vestuario expresados por la sociedad josefina y la griega en estos espacios públicos.

Según lo relata Adela Gómez Cordero, la filarmonía de Grecia: «Era municipal, había un director de banda, hacían concierto los domingos a las 5 de la tarde, lo que se llamaba el recreo, y en la noche la retreta. Se iba mudado con una flor aquí en el pecho». ${ }^{39}$ De la misma forma, Fe Vega Barrantes, hija de un secretario municipal, expone que a sus 81 años todavía recuerda que la filarmonía: «Tocaba los jueves y los domingos, daban recreo y retreta, el recreo para los niños y la retreta para los adultos»..40

Otra forma de divertirse y aprovechar los ratos de ocio era asistir al teatro. En 1920 surgen las primeras iniciativas de poner en funcionamiento un teatro en Grecia. En ese año la municipalidad otorgó a los comerciantes Juan Gonzalo Vega

35 Entrevista a Álvaro Hidalgo Ramírez, vecino de Grecia distrito central, Grecia, 18 de mayo de 2001.

36 Entrevista a Antonio Soto Barrantes, vecino de Grecia distrito central, Grecia, 28 de mayo del 2001.

37 Morales Alfaro, 23.

38 Florencia Quesada Avendaño, 192.

39 Ibíd.

40 Entrevista a Fe Vega Barrantes, vecina de Grecia distrito central, Grecia, 25 de mayo de 2001. 
y Raimundo Riggioni permiso para establecer el negocio del teatro por 15 años, excluyéndolos del pago de impuestos por un período de dos años. ${ }^{41}$ Las personas recuerdan el negocio de Juan Gonzalo Vega como un tipo salón cine. Mientras conciben al de Raimundo Riggioni como un local con más carácter de teatro.

$\mathrm{Al}$ respecto, Adela Gómez Cordero, quien disfrutaba el hecho de asistir al teatro, describe las características de ambos centros de esparcimiento de la siguiente forma:

Había uno de don Raimundo Riggioni, el Teatro Riggioni, después había un teatro de don Gonzalo Vega, era un salón cine. Es que es distinto un salón cine a un teatro, la diferencia es que el teatro tiene sus escenarios. Ese teatro Riggioni era sencillo, no era un teatro lujoso, pero había una cosa extraordinaria ahí que eran los telones del escenario. ${ }^{42}$

Ibeth Barrantes Castro, hija de un agricultor de la zona de Río Cuarto y esposa de un zapatero comunista, recuerda particularmente con cuánto dinero se debía disponer para el disfrute del teatro: «El de Raimundo Riggioni, yo recuerdo que cuando yo estaba en la escuela se pagaba 6 reales, o sea 75 centavos, que yo casi nunca los tenía y casi nunca iba, porque 75 centavos para uno era un capital, pero sí la gente del centro»». ${ }^{43}$ Por su parte, Fe Vega Barrantes alude a que ella sí frecuentaba el teatro con el aporte paterno de una peseta: «Mi papá me daba una peseta, "tome la peseta de la entrada, y un 10 para que se compre un maní", me decía». ${ }^{44}$

En los teatros josefinos también se exhibían películas, pues es hasta finales de 1920 que se promueve en el país la construcción de edificios especializados para cines. ${ }^{45} \mathrm{Al}$ respecto, según indica Álvaro Hidalgo Ramírez, la gente del centro del cantón solía asistir al teatro de Gonzalo Vega: «A ver las famosas series que creaban un gran suspenso entre el público, pues era una película divida en tres partes que se proyectaba durante tres domingos seguidos»». ${ }^{46}$

Este comentario explica por qué razón, tal y como lo detalla Adela Gómez Cordero, el teatro de Gonzalo Vega era concebido como un «salón cine», por lo que posiblemente esté haciendo referencia al «salón teatro». En San José antes de 1940 los tres primeros cines conocidos como «salón teatro», en los que se proyectaban películas, fueron el salón teatro La Merced, el salón teatro Colón y el salón teatro Olimpia. ${ }^{47}$ De acuerdo con Patricia Fumero entre 1920 y 1924 se habilitó en Grecia un centro de exhibición cinematográfica, ${ }^{48}$

41 Municipalidad de Grecia, Libro de Actas No5, Sesión IX y X (4 de abril de 1920), f 126-129.

42 Ibíd.

43 Ibíd.

44 Ibíd.

45 Quesada Avendaño, 60, 243.

46 Ibíd.

47 Patricia Fumero Vargas, Teatro público y Estado en San José (1880-1914) (San José, Costa Rica: EUCR, 1996).

48 Patricia Fumero Vargas, Cultura y sociedad en Costa Rica, 1914-1950, Cuadernos de Historia de las Instituciones n. ${ }^{\circ}$ 16. San José, Costa Rica: EUCR, 2005. 
el cual quizá sea el teatro de Gonzalo Vega donde se exhibían películas, como lo indica Álvaro Hidalgo. ${ }^{49}$

Asimismo, quienes asistían al Teatro Riggioni recuerdan con qué emoción se esperaba la asistencia de compañías de dramas invitadas por la municipalidad. Adela Gómez Cordero menciona que en: «Esa época venían compañías españolas a Grecia y las entradas valían un colón»». ${ }^{50}$ Una de las compañías invitadas fue la compañía de dramas y comedias de Ángela Liaño, la cual estuvo en Grecia en 1928 y de cuyas funciones el periódico La Prensa comentaba: «La compañía de Ángela Liaño con gran éxito ha dado tres funciones en el Teatro Riggioni, las cuales han gustado mucho al público griego que es muy culto y tiene mucho gusto por lo bueno». ${ }^{51}$

Junto a la filarmonía y al teatro, la comunidad griega disfrutaba de las fiestas cívicas realizadas para celebrar cualquier tipo de acontecimiento considerado importante y digno de festejarse. Por ejemplo, hacia 1929, después de concluida la construcción de la cañería de la ciudad y con el entusiasmo de contar ya con una carretera entre Alajuela y Grecia, se decide inaugurar tales alcances con festejos cívicos. ${ }^{52}$

El juego político fue otro motivo más para disfrutar y festejar. Don José Ángel Monge González, quien de niño trabajó en la hacienda de los Niehaus y se dedicó en su juventud a la zapatería y a la música, asegura que en ese entonces cada vez que había elecciones políticas en las esquinas diagonales del parque se solían: «Poner de pie, sobre las mesas, los partidarios de los distintos partidos a dar vivas a sus candidatos, y la gente celebraba». ${ }^{53}$

Para Mario Riggioni estas campañas políticas abrían espacios amenos para que la gente se reuniera en el parque y en el mercado a escuchar a los oradores de sus partidos políticos: «La gente salía los domingos de misa de 9 de la mañana, y ahí en el parque ponían una mesa y se subía un orador, y ahí llegábamos alrededor de cualquier partido que fuera, a dar vivas al partido». ${ }^{54}$ La fotografía 7 permite observar al expresidente Otilio Ulate Blanco cuando en la década de 1960 visitó el cantón de Grecia y convocó a una buena parte de griegos en los alrededores de la antigua Plaza Colón.

51 La Prensa, «La Compañía de Ángela Liaño en Grecia», 11 de enero de 1928, 5.

52 Municipalidad de Grecia, Libro de Actas N. ${ }^{\circ}$ 7, Sesión XXV (9 de octubre de 1929), f. 475.

53 Entrevista a José Ángel Monge González, vecino Grecia distrito Central, Grecia, 24 de mayo de 2001.

54 Ibíd. 
Fotografía 7. Expresidente Otilio Ulate en la antigua

Plaza Colón, Grecia (1960)

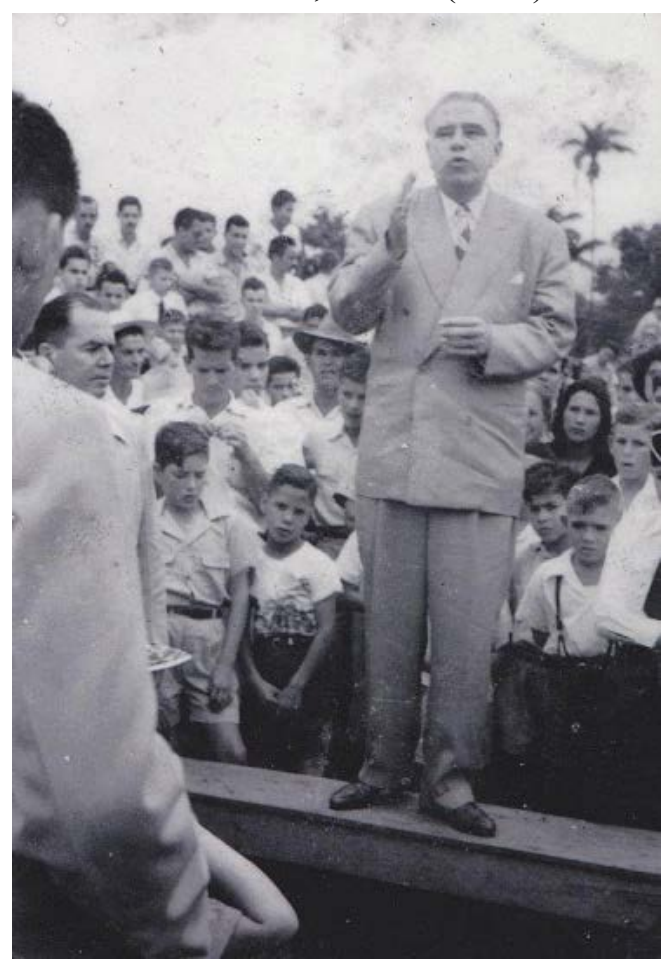

Fuente: Facebook "El tobogán de Cantinflas", https://www.facebook.com/tobogandecantinflasdegrecia/photos/a.1688258194768630/1688258984768551/?type=3\& theater. Colección personal de José Segundo Campos Aguilar.

Así entre retretas y recreos, a través del teatro, y mediante los encuentros políticos, la comunidad griega fue estableciendo prácticas sociales vinculadas al placer y al goce de su tiempo libre. Estas manifestaciones de ocio y recreación se fortalecieron con la apertura de los clubes sociales, los que, a su vez, evidenciaron una clara fragmentación socioeconómica y cultural de la sociedad griega.

\section{La flor innata griega entre clubes sociales y bailes de sociedad}

La creación de clubes se promovió en el país en las últimas décadas del siglo XIX y su conformación estuvo relacionada con el desarrollo de una cultura urbana exclusiva, y una sociabilidad eminentemente masculina. ${ }^{55}$ En Grecia durante la década de 1920 se fundaron tres clubes sociales: el Centro de Obreros, El Club de Amigos y el Grecia Fútbol Club. Aproximadamente, en 1921 fue fundado el

55 Quesada Avendaño, 213 y 2015. De acuerdo con esta autora, en la ciudad de San José durante la década de 1920 existían el Club Alemán, el Internacional, el Katharina, y el Athletic. 
Centro de Obreros, el Centro de Amigos se fundó en $1923,{ }^{56}$ y en 1925 el Grecia Fútbol Club, conocido popularmente como el Grecia FC..$^{57}$ Cada uno de estos clubes funcionaba con socios fundadores, quienes los establecieron con fines recreativos y para el entretenimiento de diversos grupos sociales de la comunidad griega.

El Centro de Obreros fue fundado por zapateros, ebanistas, sastres, mecánicos y jornaleros. Este club se constituyó como un centro mutualista que auxiliaba a sus asociados en caso de matrimonio, enfermedad o muerte. ${ }^{58}$ Por su parte, el Centro de Amigos fue establecido por comerciantes, funcionarios públicos de la municipalidad y dueños de ingenios y trapiches. Para formar parte de este club los asociados debían aportar una suma cercana a los 25 colones. El pago de dicha cuota les permitía el disfrute de los juegos de mesa — naipe, billar, ajedrez, dominó, entre otros-, así como asistir a los conocidos bailes de etiqueta, famosos por la elegancia de sus trajes, música y decoración. ${ }^{59}$

Los afiliados del Centro de Amigos se reunían en un local ubicado frente al costado oeste del parque. El lunes 2 de febrero de 1970 ese antiguo edifico, el cual se observa en la fotografía 8 que data de aproximadamente de 1930, fue destruido por un incendio y quedaron en pie únicamente sus paredes. Otras nueve construcciones resultaron afectadas o destruidas por el fuego, entre ellas algunas tiendas y bufetes, un estudio fotográfico, una ferretería, una cantina y una sastrería ${ }^{60}$

Fotografía 8. Antiguo edificio del Centro de Amigos, Grecia (1930)

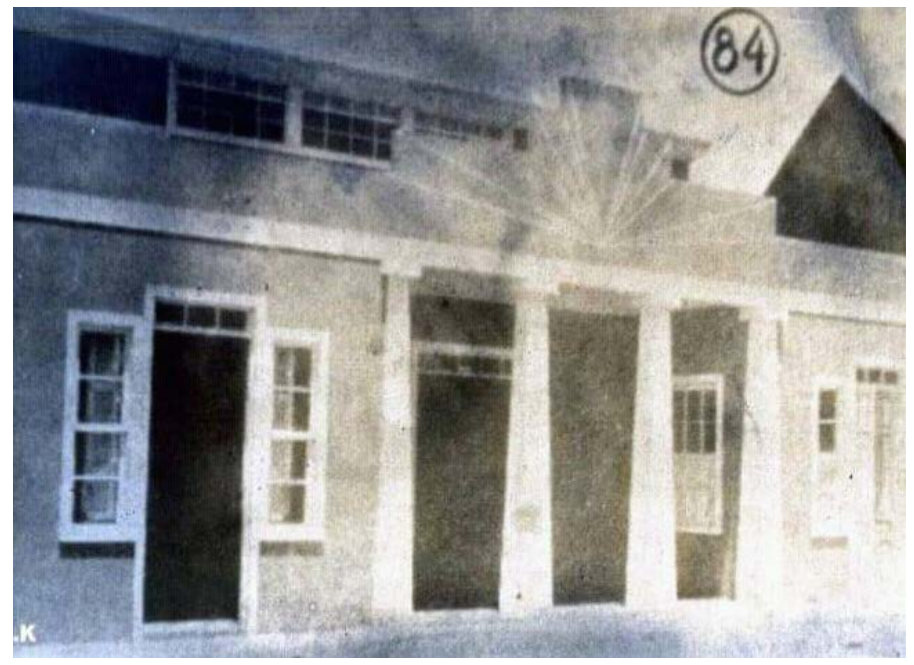

Fuente: Facebook "Personajes de Grecia", https://www.facebook.com/PersonajesGrecia/. Página administrada por Rodolfo Barillas Acosta. Diseñador gráfico y fotógrafo. Fecha aproximada.

56 Fechas aproximadas aportadas por las personas entrevistadas.

57 Grecia Fútbol Club, Libro de Actas, Tomo I (1 de diciembre de 1925.), f 1.

58 Morales Alfaro, 35, 41.

59 Ibíd.

60 La Nación, «Cuantiosas pérdidas por incendio ayer en Grecia», 3 de febrero de 1970, 10. 
Por su parte, el Grecia Fútbol Club se conformó como una asociación que pedía como requisito para ingresar a ella, en carácter de socio fundador, el pago de una cuota de 10 colones. Para aquel que sin ser socio deseaba pagar un boleto de entrada al club, se le cobraba una suma de tres colones. ${ }^{61}$ Las asociaciones deportivas o clubes deportivos experimentaron un auge en el país a partir de 1904, estos fueron fundados por varones con el fin de organizar juegos, bailes y paseos. ${ }^{62}$

Específicamente en el caso griego, al igual que el Centro de Amigos, los varones asociados al Grecia Fútbol Club eran dueños de diversos puestos comerciales, ingenios, trapiches y tiendas, quienes con el paso de los años habían ganado puestos importantes en la comunidad griega gracias a su posición económica. ${ }^{63}$ Este club permitió, además, el involucramiento de algunas mujeres, en su mayoría hijas, esposas o hermanas de los directivos asociados. En calidad de socias honorarias del club, las mujeres participaban en la entrega de medallas de premiación a los equipos vencedores. ${ }^{64}$

Como es claro, la asistencia a estos centros de socialización estuvo determinada por la clase social a la que se pertenecía. Así como por la posibilidad económica de cumplir con las exigencias de etiqueta y elegancia de los bailes de sociedad que de manera exclusiva realizaba el Centro de Amigos. Estas relaciones de selección o exclusión fueron practicadas también en los clubes josefinos constituidos a finales del siglo XIX, en los que la edad, el sexo y la condición socioeconómica se consideraron requisitos para formar parte de tales asociaciones, las cuales además cobraban a sus miembros una cuota de inscripción y otra mensual, para reunirse de manera privada, a practicar juegos de sociedad como naipes, ajedrez y billar, a leer y socializar entre ellos. ${ }^{65}$

En cuanto a cómo los clubes seleccionaban quién podía participar en sus actividades, Álvaro Hidalgo Ramírez, que por varios años administró el Grecia FC, explica el derecho de participar en sus actividades de ocio de la siguiente manera: «La ciudad se dividía en tres sectores, el obrero, la clase media que era el Grecia FC, y la clase alta que era el Centro de Amigos, en orden de menor a mayor. En el Centro de Amigos se daban el lujo de escoger quién iba y quién no iba a un baile». ${ }^{66}$

Por el contrario, al Centro de Obreros podía asistir toda persona y no únicamente los obreros y sus familias. Este club era frecuentado, según recuerda Manuel Antonio Soto Barrantes: «Por toda la gente de Grecia que no era de la sociedad. Iban a festejar cumpleaños y matrimonios, $\mathrm{o}$ a disfrutar de los bailes». ${ }^{67}$

61 Grecia Fútbol Club, Libro de Actas, Tomo I (3 de diciembre de 1925.), f 3.

62 Enríquez Solano, 131.

63 Juan Rafael Morales Alfaro y Álvaro Hidalgo Ramírez, Ibíd.

64 Grecia Fútbol Club, Libro de Actas, Tomo I (4 de marzo de 1930), f 63.

65 Quesada Avendaño, 215.

66 Álvaro Hidalgo Ramírez, Ibíd.

67 Manuel Antonio Soto Barrantes, Ibíd. 
Para Juan José Arroyo Solano, zapatero de 84 años, quien se dedicó en su juventud al diseño de sombreros y, posteriormente, a la producción de zapatos finos de dama y caballero, la diferencia entre los clubes se limitaba:

\begin{abstract}
No exactamente a clases sociales, sino a las culturas sociales, generalmente el asistente se distingue por cultura. A los centros de obreros íbamos nosotros, los que nos mudábamos los sábados o los domingos, y nos gustaba ir a dar una vueltilla para bailar, ahí se celebraban bailes muy bonitos. Nos tomábamos nuestros qüisquitos, los obreros podíamos vestir casimir. ${ }^{68}$
\end{abstract}

No sucedía lo mismo con el Centro de Amigos, más exclusivo y privado por el tipo de personas que a él concurrían. Adela Gómez Cordero recuerda que por ser hija de uno de los fundadores de la asociación, ella y sus cinco hermanos podían frecuentar este club, pues a él solo asistía: «Lo que en el pueblo podía llamarse, que se decía la sociedad, y sólo los hijos de los socios podían entrar». ${ }^{69}$ En opinión de Juan José Arroyo Solano, este club representaba: «A personas muy cultas, muy decentes, eran familias que se distinguían por sus condiciones de vida diferente». ${ }^{70}$

De la misma forma, Ibeth Barrantes Castro recuerda que: «Esas personas conformaban la sociedad. Eran un grupo selecto sencillamente porque terminaron la primaria y porque se podían poner zapatos, y tenían algún puestillo en la municipalidad, gente así, que tenía cierta posición». ${ }^{71}$ De allí, que este club haya sido considerado el sitio ideal para la gente de mejor educación, ${ }^{72}$ para personas de la high life ${ }^{73}$ y en definitiva, para la flor innata de la época. ${ }^{74}$

Las actividades de ocio que principalmente se disfrutaban en todos estos clubes eran los juegos de mesas y los conocidos bailes de etiqueta o bailes populares. En cuanto a los juegos de mesa, que en ocasiones los clubes los transformaban en campeonatos de ajedrez y tablero, Álvaro Hidalgo Ramírez menciona que los varones griegos desde muy jóvenes:

Aprendían los juegos de azar, por lo general se iba a jugar uno a los potreros, porque en los sitios públicos no lo permitían al menor de edad, ya el mayor de edad jugaba en los clubes. En los clubes existían los conocidos semi deportivos como billar, dominó, tablero, ajedrez, trencillo y naipes. ${ }^{75}$

La fotografía 9 permite observar a un grupo de caballeros griegos jugando ajedrez en el Centro de Amigos aproximadamente entre 1950 y 1960.

\footnotetext{
68 Entrevista a Juan José Arroyo Solano, vecino de Grecia, distrito Central, Grecia, 19 de mayo de 2001.

69 Adela Gómez Cordero, Ibíd.

70 Juan José Arroyo, Ibíd.

71 Ibeth Barrantes Castro, Ibíd.

72 Adela Gómez Cordero, Ibíd.

73 Juan Rafael Morales Alfaro, Ibíd.

74 Manuel Antonio Soto Barrantes, Ibíd.

75 Álvaro Hidalgo Ramírez, Ibíd.
} 
Entre ellos se encuentran los señores Luis Ramírez Villalobos, Mario Riggioni y el conocido Pepe Vega.

Fotografía 9. Caballeros griegos jugando ajedrez en el local del Centro de Amigos, Grecia, aproximadamente 1950-1960

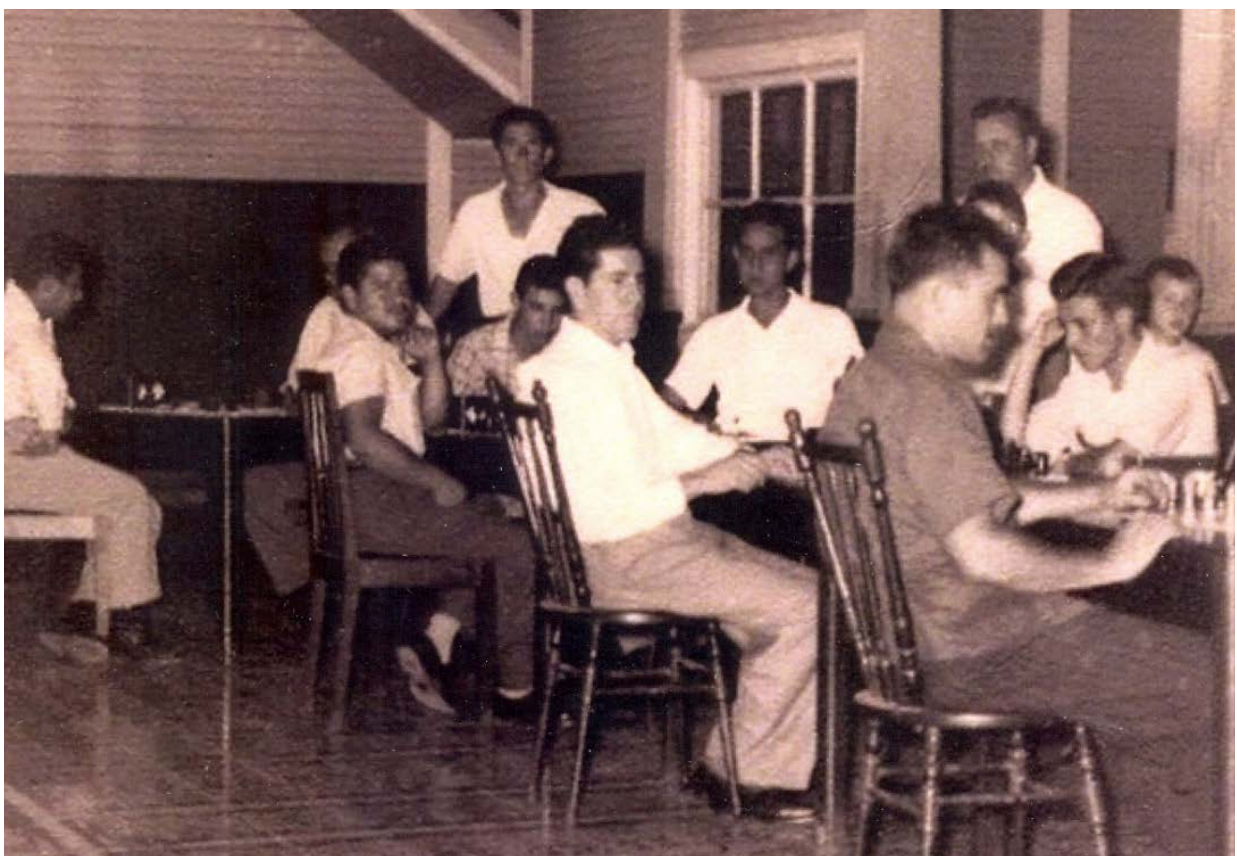

Fuente: Facebook "Personajes de Grecia”, https://www.facebook.com/PersonajesGrecia/. Página administrada por Rodolfo Barillas Acosta. Diseñador gráfico y fotógrafo. Fecha aproximada.

Los juegos de mesa además solían ser practicados en el centro del parque. De hecho, en 1935 la municipalidad externa su preocupación por la presencia de estos juegos en las inmediaciones de la parte central del parque, en los siguientes términos: «Dan un feo aspecto a un lugar destinado a las diversiones de la sociedad». Por esta razón, la municipalidad recomendó medidas higienistas como: «Situar mesas de juego fuera del parque y dentro ventecitas ligeras de confeti, frutas, etc.». ${ }^{76}$

Aunque los juegos de mesas también eran practicados en el Centro de Amigos, su principal atractivo fue la formalidad y la categoría de sus bailes de etiqueta. La exclusividad se expresaba en la elegancia de los vestuarios. La etiqueta consistía en traje y corbata para los varones, y vestido largo para las

76 Municipalidad de Grecia, Libro de Actas N. ${ }^{\circ}$ 9, Sesión XXIV (8 de enero de 1935), f.279. 
damas. ${ }^{77}$ Adela Gómez Cordero fue frecuentemente invitada a los bailes del Centro de Amigos y recuerda que la invitación a los bailes de etiqueta era enviada vía correo.

La costumbre de enviar invitaciones fue practicada por los clubes josefinos. Los socios del club eran los encargados de seleccionar a las personas invitadas al baile, elaborar la lista y hacer las invitaciones. Por su parte, los varones eran los responsables de llenar los programas de las señoritas. Estos programas consistían en una libreta donde el hombre apuntaba las piezas que quería bailar con la mujer. ${ }^{78}$ En cuanto a dichos programas, Adela Gómez Cordero comenta que para ella lo más llamativo de estos bailes eran las famosas oberturas, y desde luego, los bailes de programa, los que describe de la siguiente manera:

Se desfilaba en parejas por la orilla y tocaban música seria. Se daban dos vueltas al salón, se sentaba uno, y ya después venía el baile. Se bailaban las cuadrillas que eran muy elegantes. Había bailes de programa que era un librito con todas las piezas. El 24 de setiembre, el día de la Patrona se hacía el baile lila, se iba con vestido largo. ${ }^{79}$

De la misma forma, Juan José Arroyo Solano relata cuán elegantes eran los bailes que el Centro de Amigos realizaba:

Cuando era un baile de etiqueta, cuando era un baile especial, se distinguía por el traje. El baile era todos vestidos del mismo color, los hombres y las mujeres también vestidas igual. En aquel tiempo la mujer se distinguía por un traje generalmente largo, generalmente de seda o de una tela especial muy visible con estilos de ropa muy decente. Los hombres para un baile de etiqueta iban con esmoquin. ${ }^{80}$

En relación con lo descrito, es importante considerar que hacia 1920 nuevas formas de divertirse se pusieron de moda, entre las que sobresalen los bailes de colores. Estos bailes eran anunciados con un color temático que servía de base, tanto para la decoración, como de guía para el tipo de vestuario que las damas debían lucir. ${ }^{81}$ Un claro ejemplo es el «baile obrero» efectuado en Grecia el 31 de diciembre para dar la bienvenida al año nuevo, y que convocó a las señoritas a vestirse de rosado. Al respecto, el 11 de enero de 1928 el periódico La Prensa, exponía:

Se llevó acabo por un grupo de entusiastas griegos el baile del 31 de diciembre para finalizar el año, que como un soplo se alejó. Serían las 19 horas cuando ya estaba el salón casi lleno de lindas y gentiles señoritas luciendo todas ellas el traje rosado

77 Álvaro Hidalgo Ramírez, Ibíd.

78 Quesada Avendaño, 216.

79 Adela Gómez Cordero, Ibíd.

80 Juan José Arroyo Solano, Ibíd.

81 María Clara Vargas Cullell, Práctica musical en Costa Rica (1840-1940) (Tesis de Maestría en Historia, Universidad de Costa Rica, 2000), 160. 
dando así un aspecto animado y alegre, contrastando con el adorno del salón, que por ciento fue muy gustado por la manera en que fue decorado, multitud de bombillas de color colgaban en medio de vistosas serpentinas, teniendo impresas la bienvenida con que los obreros saludaban al año nuevo. A las 8 de la noche dio principio el baile, lleno de la mejor compostura y orden, donde vimos desfilar un número bastante grande de parejas. ${ }^{82}$

Si bien es cierto los obreros contaban con el Centro de Obreros como el encargado de organizar sus bailes, estos no eran tan elegantes y exclusivos como los del Centro de Amigos. Juan José Arroyo Solano recuerda que cuando había bailes en el Centro de Obreros, los asociados del Club de Amigos: «Se presentaban ahí a bailar». ${ }^{83}$ En 1920 el comité del Centro de Obreros solicitó a la municipalidad el salón municipal para realizar un baile en celebración de la virgen de Las Mercedes, patrona del cantón, cuyo fin era que toda la comunidad griega participara. ${ }^{84}$

Álvaro Hidalgo Ramírez recuerda los bailes del Centro de Obreros como espacios de entretenimiento más populares. A su parecer estos bailes tenían la tónica de los bailes que la comunidad de Grecia disfrutaba realizar en los días festivos o fines de semana. Pues en realidad los bailes fueron, en Grecia, «algo muy corriente, se hacían bailes en un ingenio, hasta en la carretera, era algo más popularizado que ahora, pero no era lucrativo. Cuando se cobraba era cuando ya había conjuntos».$^{85}$

A partir de los recuerdos expresados por las personas entrevistadas es posible afirmar que, durante el periodo de estudio, bailes, clubes sociales y juegos de azar conformaron una identidad de clase entre obreros, agricultores y comerciantes. Se estableció, así, no solo una diferenciación social de los espacios en que estos grupos se encontraban y socializaban, sino también un autoreconocimiento entre quienes vestían de casimir y asistían a bailes populares, y quienes lucían traje y corbata, y recibían invitaciones a los coloridos bailes de sociedad.

Es importante indicar que estas expresiones de identidad de clase probablemente estuvieron, directa o indirectamente, asociadas al movimiento comunista que surgió en Grecia a partir de 1930. En el cantón, los trabajadores del calzado, los ebanistas, los peones agrícolas y algunas mujeres amas de casa fueron quienes principalmente simpatizaron con dicho movimiento social. De hecho, fue por iniciativa de estos grupos que el Centro Obrero se fundó como centro mutualista y como espacio de encuentro para toda la sociedad griega.

82 La Prensa, «Ecos del baile obrero en la Ciudad de Grecia», 11 de enero de 1928, 5.

83 Juan José Arroyo Solano, Ibíd.

84 Municipalidad de Grecia, Libro de Actas N. ${ }^{\circ}$ 5, Sesión I (4 de abril de 1920), f.126-129.

85 Álvaro Hidalgo Ramírez. 


\section{Conclusiones sobre las manifestaciones culturales del ocio en un es- pacio rural}

La presencia del teatro, el colorido de los bailes, las melodías de la filarmonía y, desde luego, la sociabilidad masculina, incentivada por los clubes, fueron parte del singular desarrollo social, cultural y urbanístico que experimentó el cantón de Grecia a partir de 1920. Estas diversas maneras en las que la comunidad griega fue ideando espacios públicos y privados para disfrutar su tiempo libre muestran dos aspectos sobresalientes. Por un lado, la apropiación de hábitos de esparcimiento semejantes a los practicados por la burguesía cafetalera josefina; y por otro, la fragmentación socioeconómica y cultural de la sociedad griega.

En el primer caso, es importante indicar que durante la segunda mitad del siglo XIX la recreación josefina estuvo relacionada con gustos europeos por el teatro, la música y los bailes. Como fruto de los avances económicos y culturales de la época, San José experimentó una expansión de centros de diversión, esparcimiento y, principalmente, de apertura de lugares propicios para la sociabilidad de la élite y el encuentro de los sectores urbanos. En tal sentido, las actividades de recreación adoptadas en el espacio rural griego muestran características similares con el modelo de vida urbano josefino.

Durante el periodo de estudio, la sociedad griega amplió los espacios de ocio y diversión a funciones de teatro, a paseos al parque, y a la participación en clubes sociales. Si bien es cierto, estas actividades contribuyeron a diversificar la vida cultural de la población, también, de una u otra forma, establecieron diferenciaciones entre «la gente del centro» y «la gente de los distritos»; o bien entre quienes se percibían como «gente de sociedad», y quienes no se distinguían así. Estas maneras de percibirse y relacionarse definieron la asistencia, el involucramiento y, en definitiva, el disfrute de las actividades de ocio y recreación al interior de la comunidad griega.

Por ejemplo, mientras retretas y recreos facilitaron el encuentro de mujeres y varones, además de obreros, agricultores y comerciantes, en un mismo espacio de entretenimiento público y gratuito; el teatro y los clubes sociales limitaron el disfrute de sus encuentros no solo al pago de cuotas, sino también a la pertenencia a una clase social. A su vez, la introducción de la música y el baile conllevaron a cambios en los patrones culturales, pues su disfrute supuso la adopción de nuevos hábitos de vestuario, de comportamiento y decorado de los espacios de encuentro.

Aunque las retretas fueron actividades dedicadas a la educación, a través de las cuales se buscó estimular la cultura del pueblo y difundir entre los sectores populares valores considerados civilizadores, también promovieron, al igual que los llamados bailes de sociedad, la adopción de nuevas prácticas de vestimenta entre los diferentes grupos sociales. Por ejemplo, la flor puesta en el pecho significó una forma de distinción entre los jóvenes del centro y los jóvenes de distrito 
que confluían a dar vueltas al parque para escuchar la filarmonía. En tanto, el vestido largo y el traje con corbata establecieron una diferencia entre la categoría de los bailes y sus asistentes o, en el mejor de los casos, entre quienes tenían o no el privilegio de ser recibir invitaciones.

A su vez, asistir al teatro o formar parte de clubes sociales como el Centro de Amigos o el Grecia Futbol Club dependió del poder adquisitivo de la persona. Contar con al menos una peseta para asistir a las funciones teatrales no fue sencillo para quienes vivían lejos del centro del cantón. Las personas que solían asistir se autoreconocen como hijos e hijas de comerciantes y funcionarios públicos quienes contaban con ciertas ventajas económicas para pagar la entrada al teatro o al «cine salón» $\mathrm{y}$, además, consumir algún producto durante o después de las funciones.

De igual forma, el reconocimiento como un asociado de estos clubes de renombre social dependió del pago de cuotas de inscripción, además del cumplimiento de códigos de vestuario no asequible para toda la población. Por tanto, mientras se adoptaban nuevas formas de diversión y entretenimiento, y el espacio rural griego adquiría más carácter de ciudad urbana, la sociedad griega experimentaba una ligera pero evidente fragmentación sociocultural.

\section{Bibliografía}

Archivo Nacional de Costa Rica (ANCR). Fondo Congreso, año 1911, serie 76, folio 2 .

ANCR. Fondo Congreso, año 1920, serie 11727, folio 1.

ANCR. Fondo Congreso, año 1934, serie 1750, folio 1.

ANCR. Fondo Congreso, año 1936, serie 17609, folio 5.

ANCR. Fondo Municipal, año 1940, serie, 016633, folio .332.

ANCR. Fondo Fotografías, siglo XIX y XX, serie 74338.

Carvajal Alvarado, Guillermo y Jorge Vargas Cullell. «El surgimiento de un espacio urbano-metropolitano en el Valle Central de Costa Rica (19501980)». Anuario de Estudios Centroamericanos, 13, n. ${ }^{\circ} 1$ (1987). https:// revistas.ucr.ac.cr/index.php/anuario/article/view/2866.

Cuenca Cabeza, Manuel y Eduardo Aguilar Gutiérrez. El tiempo del ocio: transformaciones y riesgos en la sociedad apresurada. Bilbao, España: Universidad de Deusto, 2009.

Elizalde Soto, Rodrigo. «Resignificación del ocio. Aportes para un aprendizaje transformacional». Polis: Revista Latinoamericana, n. ${ }^{\circ} 25$ (2010). http:// journals.openedition.org/polis/642.

Enríquez Solano, Francisco José. Diversión pública y sociabilidad en las comunidades cafetaleras de San José: el caso de Moravia (1890-1930). Tesis de Maestría en Historia, Universidad de Costa Rica, 1998.

Fumero Vargas, Patricia. Teatro público y Estado en San José (1880-1914). San José, Costa Rica: EUCR, 1996. 
- Cultura y sociedad en Costa Rica, 1914-1950, Cuadernos de Historia de las Instituciones n. ${ }^{\circ}$ 16. San José, Costa Rica: EUCR, 2005.

Gerlero, Julia. «Diferencias entre ocio, tiempo libre y recreación: lineamientos preliminares para el estudio de la recreación». Ponencia presentada en el I Congreso Departamental de Recreación de la Orinoquia Colombiana. Villavicencio, Meta. 20, 21 y 22 de octubre de 2005. Servicio de la Fundación Colombiana de Tiempo Libre y Recreación. Fundación Latinoamericana de Tiempo Libre y Recreación (FUNLIBRE) Costa Rica México. http://www.redcreacion.org/documentos/cmeta1/JGerlero. html\#Uso_apropiado_del_documento.

Gomes, Christianne. «El ocio y la recreación en las sociedades latinoamericanas actuales». Polis: Revista Latinoamericana, 13, n. ${ }^{\circ} 37$ (2014). http://journals.openedition.org/polis/9905.

—. «Ocio, recreación e interculturalidad desde el 'Sur' del mundo: desafíos actuales». Polis: Revista de la Universidad Bolivariana (Chile) 9, n. ${ }^{\circ} 26$ (2010). doi: http://dx.doi.org/10.4067/S0718-65682010000200010.

Goytia Prat, Ana. «El influjo del tiempo en la experiencia de ocio de los vascos. Transformaciones en los últimos 15 años». En: El tiempo del ocio: transformaciones y riesgos en la sociedad apresurada. Bilbao, España: Universidad de Deusto, 2009.

Grecia Fútbol Club. Libro de Actas, Tomo I (1 de diciembre de 1925.), f 1.

Grecia Fútbol Club. Libro de Actas, Tomo I (3 de diciembre de 1925.), f 3.

Grecia Fútbol Club. Libro de Actas, Tomo I (4 de marzo de 1930), f63.

Hall, Carolyn. El café y el desarrollo histórico-geográfico de Costa Rica. San José, Costa Rica: Editorial Costa Rica, 1982.

La Nación. «Cuantiosas pérdidas por incendio ayer en Grecia», 3 de febrero de 1970, 10.

La Prensa. «Ecos del baile obrero en la Ciudad de Grecia», 11 de enero de 1928, 5. La Prensa. «La Compañía de Ángela Liaño en Grecia», 11 de enero de 1928, 5. La Tribuna. «A través de la República, Grecia», 10 de marzo de 1926, 7.

Maroto Barquero, Carlos Alberto. Significado histórico, social y económico del café y la caña de azúcar en el cantón de Grecia (1892-1978). Tesis de Licenciatura en Historia, Universidad de Costa Rica, 1979.

Ministerio de Salud. Estrategia nacional para un envejecimiento saludable basado en el curso de vida 2018-2020. Dirección de Planificación Estratégica y Evaluación de las Acciones en Salud, 1'a ed., San José, Costa Rica, 2018.

Morales Alfaro, Juan Rafael. Escribo para recordar. San José, Costa Rica: ASEPROLA-Universidad Estatal a Distancia, 2000.

Municipalidad de Grecia. Libro de Actas N. ${ }^{\circ}$ 5, Sesión IX y X (4 de abril de 1920), f. 126-129. 
Municipalidad de Grecia. Libro de Actas N. . 6, Sesión III, Artículo I (24 de enero de 1927), f. 545.

Municipalidad de Grecia. Libro de Actas No 6, Sesión II, Artículo VIII (24 de enero de 1927), f. 545-547.

Municipalidad de Grecia. Libro de Actas N. ${ }^{\circ}$ 6, Sesión X, Artículo XXI (14 de febrero de 1927), f. 563.

Municipalidad de Grecia. Libro de Actas N. ${ }^{\circ}$ 7, Sesión XXV (9 de octubre de 1929), f. 475.

Municipalidad de Grecia. Libro de Actas N. ${ }^{\circ}$ 9, Sesión VI, Artículo XIII (3 de julio de 1934), f. 169.

Municipalidad de Grecia, Libro de Actas N. ${ }^{\circ}$ 5, Sesión XLIV, Artículo XIII (27 de junio de 1945), f. 132-133.

Quesada Avendaño, Florencia. La vida interior y exterior del Barrio Amón. Arquitectura, familia y sociabilidad burguesa. Nueva segregación urbana en la capital costarricense (1900-1935). Tesis de Maestría en Historia, Universidad de Costa Rica, 1998.

Vargas Cullell, María Clara. Práctica musical en Costa Rica (1840-1940). Tesis de Maestría en Historia, Universidad de Costa Rica, 2000.

—. De las fanfarrias a las salas de concierto. Música en Costa Rica (18401940). San José, Costa Rica: EUCR, 2004.

\section{Fuentes orales}

Entrevista a Juan José Arroyo Solano, vecino de Grecia, distrito Central, Grecia, 19 de mayo de 2001.

Entrevista Ibeth Barrantes Vega, vecina de Grecia distrito central, Grecia, 24 de octubre de 2001.

Entrevista a Adela Gómez Cordero, vecina de Grecia distrito central, Grecia, 25 de mayo de 2001.

Entrevista a Álvaro Hidalgo Ramírez, vecino de Grecia distrito central, Grecia, 18 de mayo de 2001.

Entrevista a José Ángel Monge González, vecino Grecia distrito Central, Grecia, 24 de mayo de 2001.

Entrevista a Juan Rafael Morales Alfaro, vecino de Grecia, distrito central, Grecia, 25 de mayo de 2001.

Entrevista a Mario Riggioni, vecino de Grecia distrito central, Grecia, 26 de setiembre de 2001.

Entrevista a Antonio Soto Barrantes, vecino de Grecia distrito central, Grecia, 28 de mayo del 2001.

Entrevista a Fe Vega Barrantes, vecina de Grecia distrito central, Grecia, 25 de mayo de 2001.

Colección fotográfica de la familia Ramírez Arguedas, Grecia 2019. 
